\title{
Can procedural and substantive elements of decision-making be reconciled in assessments of mental capacity?
}

\author{
Natalie F. Banner \\ Centre for the Humanities and Health, King's College London
}

\begin{abstract}
Capacity legislation aims to protect individual autonomy and avoid undue paternalism as far as possible, partly through ensuring patients are not deemed to lack capacity because they make an unwise decision. To this end, the law employs a procedural test of capacity that excludes substantive judgments about patients' decisions. However, clinical intuitions about patients' capacity to make decisions about their treatment often conflict with a strict reading of the legal criteria for assessing capacity, particularly in psychiatry. In this article I argue that this tension arises because the procedural conception of capacity is inadequate and does not reflect the clinical or legal realities of assessing capacity. I propose that conceptualising capacity as having 'recognisable reasons' for a treatment decision provides a practical way of legitimately incorporating both procedural and substantive elements of decision-making into assessments of capacity.
\end{abstract}

Capacity legislation is committed to the avoidance of undue medical paternalism by stipulating that the assessment of capacity focuses solely on the process by which a patient reaches a decision, irrespective of the content of that decision. Little attention has been paid to how procedural notions of capacity are supposed to function, as they rely on vague and underspecified normative notions such as 'balancing' or 'weighing' information. In this article I question whether the procedural elements of decision-making can in principle be considered separately from the substantive contents of beliefs and values that inform the decision outcome. In doing so I make two claims. First, on a solely procedural view of the relation between all the factors entering into the process and a decision outcome, one cannot reliably judge whether the decision-making process is undermined by a mental impairment. Second, recognising that substantive features of decisionmaking do underpin assessments of capacity does not entail that paternalistic evaluative judgments about the contents of beliefs or values need to be made. If a compromise view is taken that recognises the interplay between procedural and substantive elements of decision-making, a richer and more sophisticated approach to capacity can be developed, based on the claim that capacity can be thought of in terms of having 'recognisable reasons' for one's decisions. This approach is not value-neutral, but nonetheless is capable of avoiding charges of unwarranted paternalism.

\section{The procedural conception of capacity and the Mental Capacity Act}

In England and Wales, the Mental Capacity Act $2005(\mathrm{MCA})^{\mathrm{I}}$ has codified a test of decision-making capacity that aims to balance protection for vulnerable individuals with the right to autonomy. This

I Mental Capacity Act 2005 c. 9. Available at: http://www.opsi.gov.uk/acts/acts2005/pdf/ukpga_20050009_en.pdf. 
right is retained wherever an individual has the ability to make a decision for himself about how he wishes to be treated. The MCA and its associated Code of Practice explicitly state that capacity assessment should be based on evaluating the processes a patient uses to arrive at a decision rather than the content of the decision itself: "What matters is [the] ability to carry out the processes involved in making the decision - and not the outcome' (Department of Constitutional Affairs, 2007, Code of Practice, Section 4.2).

Furthermore, the guiding principles of the MCA stipulate that '[a] person is not to be treated as unable to make a decision merely because he makes an unwise decision' (MCA, Section I(4)). The competently made unwise decision should stand even if family members, carers or clinicians are unhappy with that decision. Such a right has been enshrined in English common law since I850 (Ashton, Letts, Oates and Terrell, 2006). The adoption of this 'procedural' notion of capacity has a very clear purpose in law: to avoid as far as possible the threat of medical paternalism, which would lead to a patient's right to autonomy being overruled if a clinician does not agree that the patient has made the right or best decision. This notion of capacity can be distinguished from a 'substantive' view, in which the content of the decision outcome does play a role in ascertaining capacity. Conceptually, the MCA implies that the form of the decision-making process can and should be separated from its content. In practical terms, this means that in the context of assessing mental capacity, clinicians ought not to judge the content of the decision as being good or bad, wise or unwise, but only assess the process by which the decision has been reached. However, whilst indicating that judging the decision outcome is an inappropriate way to approach determining capacity, the Law Commission report that preceded the development of the MCA highlighted that a substantive approach was in fact common in clinical practice, since the decision outcome sometimes affects the clinician's judgment of capacity: '... if the outcome is to reject a course which the doctor has advised then capacity is found to be absent' (Law Commission, I995, paragraph 3.4).

In order to have capacity one must be capable of making epistemic commitments, namely beliefs, and evaluative commitments, namely values and desires, and acting upon those commitments. The procedural view does not, however, make any claims about what those commitments ought to be. In theory, an assessor need not share the specific beliefs or values held by the patient, nor agree with their decision in order to recognise how the decision-making process is formed and whether or not it might be impaired.

Under normal circumstances where a person's ability to make a decision is not in question, he has an inalienable right to decide whatever he wants, even if this is likely to result in his own death or disability. Case-law dictates that no reasons, justifications or rationalisations need to be provided to substantiate or explain his decision:

'... the patient's right of choice exists whether the reasons for making that choice are rational, irrational, unknown or even non-existent.'2

'A mentally competent patient has an absolute right to refuse to consent to medical treatment for any reason, rational or irrational, or for no reason at all, even where that decision may lead to his or her own death.'3

Re $M B$ established that decisions based on irrational beliefs do not indicate a lack of capacity, unless the belief is caused by a mental impairment. The implication here is that even a decision that is 'so

2 Lord Donaldson in Re T (Adult: Refusal of Treatment) [1992] 4 All E.R. 649, at 653.

$3 \operatorname{Re} M B$ (Medical Treatment) [I997] 2 F.L.R. 426, at 426. 
outrageous in its defiance of logic or of accepted moral standards ... [that] ... no sensible person ... could have arrived at it'4 does not undermine a person's capacity. Making what is judged to be an irrational decision, or basing it on irrational beliefs or values, does not, per se, entail a person lacks capacity: the burden of proof is on ascertaining whether the decision is the product of a mental impairment. In the MCA test for capacity there is thus a significant weight placed on the idea that it is, in fact, possible to ascertain whether a decision-making process is being disrupted by a mental impairment, without appealing to the content of the decision outcome to support the judgment.

In clinical practice, this is an exceptionally challenging judgment to make. Where cognitive impairments are evident, as in advanced dementia or a state of delirium, capacity assessment may be straightforward: it may be clear that the patient lacks the ability to understand the treatment options being offered, or engage in the decision process at all. However, in psychiatric settings some patients may not be obviously cognitively impaired, for example, in patients diagnosed with anorexia or depression (Owen, Freyenhagen, Richardson and Hotopf, 2009b). Nonetheless their capacity is called into question on account of the decisions they wish to make, such as refusing potentially life-saving medical treatment.

Critiques of procedural accounts of capacity have drawn attention to the fact that they do not match up with clinical experience: clinicians may consider a patient to lack capacity even if he ostensibly passes all the procedural requirements of the test (Culver and Gert, 2004). This is particularly true in mental health settings. Often it is precisely the decision outcome, such as a treatment refusal, that alerts clinicians to the fact that there may be a mental impairment influencing the decision-making process: 'doctors faced with a refusal of consent have to give very careful and detailed consideration to the patient's capacity to decide ... .5 Patients suffering from anorexia are frequently able to articulate and understand their circumstances and understand the treatment that is being proposed. (Tan, Stewart, Fitzpatrick and Hope, 2006; Tan, Hope and Stewart, 2003) conducted in-depth interviews with anorexic patients, revealing a complex picture of coherent decision-making, but which frequently involved distorted evaluative commitments. Such patients sometimes also hold patently false beliefs about their weight (Viglione, Muratori, Maestro, Brunori and Picchi, 2006). These patients were able to tick all the necessary procedural boxes for demonstrating capacity, providing a logical account of their decision-making, but refused treatment that may have prevented serious deterioration in health and possibly their death. Under these circumstances, clinicians often feel there is a significant question over whether such patients have capacity to make treatment decisions (Tan and Hope, 2008).

Thus there appears to be a tension between the procedural legal criteria for assessing capacity and the experience of clinicians in judging difficult psychiatric cases, which highlights a problem for translating the law into clinical practice. Putting the practical realities of capacity assessment to one side for a moment, I wish to consider how a purely procedural account of capacity is supposed to function in principle: What distinguishes a process of decision-making that is disrupted by a mental impairment from one that is not? If a procedural account of capacity is to be viable, it had better be possible to draw this distinction independently of evaluating the content of the decision outcome, and the beliefs and values that have informed it.

\section{How are procedural accounts supposed to work?}

The most conceptually difficult criterion of the capacity test to determine is commonly held to be that of 'using or weighing' information. A person is able to use or weigh information in coming to

$4 \quad \operatorname{Re} M B$ at 437.

$5 \quad \operatorname{Re} T$ at 662. 
a decision insofar as he can consider the risks, benefits and consequences of receiving or not receiving treatment, and take into account his own beliefs and system of values in determining what to do (Ashton et al., 2006). This is consistent with an element in many tests of capacity referred to as the ability to 'reason' (e.g. Grisso, Appelbaum and Hill-Fotouhi, I997). There is surprisingly little discussion in the theoretical and empirical literature on capacity detailing either what is meant by using or weighing information, or what constitutes fulfilment of this criterion. In some of the legal precedents underpinning the MCA reference is made to 'balancing' information, ${ }^{6}$ but this does not help clarify the criterion any further.

In assessing whether someone is using or weighing information, one needs to be aware of what information is entering into the decision-making process. Whilst the relevant treatment information imparted by the clinician will be an important part of this, other factors such as a value system and personal beliefs will also be influential in determining the decision outcome (Stauch, Wheat and Tingle, 2006, p. I26). On the procedural view, however, the contents of these beliefs and values will not themselves be evaluatively judged.

The capacity criteria require more than an understanding of the information given about a potential treatment or course of action; they require an indication that this information has been used appropriately to influence the decision outcome. This process might be envisaged as an information-processing black box: a visual metaphor common to cognitive psychology. On this model, various factors serve as inputs to decision-making, including the information given, along with a person's known beliefs, values, desires, fears, and so on. These are weighed up in a process whereby various cognitive mechanisms operate upon the information received, and subsequently an output emerges in the form of a decision about what the person wishes to do. How, though, could the operation of this process be judged?

It is essential to the procedural test of capacity that examining the process of decision-making can enable an observer to distinguish between these two possibilities, since they differ in ways that are significant for assessment: the former indicates fulfilment of the using or weighing information criterion, whereas the latter might not. Yet all that a clinician has to go on is the outcome of the decision, and some awareness of the input factors, many of which will be unknown to the clinician and perhaps even to the patient himself. It would seem that judgments about the decision-making process must be based upon the perceived normative connection between the input factors and the output: on whether or not the decision is one that, in some as yet unspecified sense, follows in the light of the person's beliefs and values (whatever they might be). There ought therefore to be a connection between the inputs and the decision outcome, if the person is to be judged to have used or weighed the information in coming to that decision. What might this connection look like on a procedural view of capacity?

\section{Procedural rationality}

Examining the internal structure of decision-making and action-guiding processes has spawned a vast conceptual and empirical research literature. Philosophical theories tend to construe reasoning and decision-making in terms of inferences from premises to conclusions, and the ability to recognise the validity of such inferences (Raz, I999). The philosopher of mind and language Donald Davidson makes explicit that an understanding of actions can be conceptualised through mapping out logical relations between beliefs, desires and actions, in the form of an inferential argument:

6 For example, Re MB; Re C (Adult: Refusal of Medical Treatment) [1994] I W.L.R. 290, and the 'Eastman' test of capacity. 
If we can characterise the reasoning that would serve, we will, in effect, have described the logical relations between descriptions of beliefs and desires, and the description of the action ... We are to imagine, then, that the agent's beliefs and desires provide him with the premises of an argument.' (Davidson, I978/2004, 85-86)

This understanding of decision-making as an inferential process also finds currency in cognitive psychology. For example, 'philosophical - psychological' (PP) rationality is a term used to describe a behaviour or action evaluated in terms of the process that led to it being performed, irrespective of the appropriateness of the ends or the outcome (Kacelnik, 2006). PP-rationality is about the integrity of information processing rather than the rationality of actions themselves (Hurley and Nudds, 2006). It therefore appears to resemble the procedural notion of capacity, and it is thus instructive to examine how research into this type of rationality has sought to distinguish rational, procedurally intact, decision-making processes from those that are not.

Empirical research into reasoning and decision-making, particularly in the cognitive sciences, has for the most part been guided by a framework whereby the connection between a set of inputs and a decision output is judged according to the dictates of an ideal of logic (see Stein, I996, for an overview of the field). For instance, cognitive psychology in this area has tended to focus on conditional and syllogistic reasoning (Eysenck and Keane, 2005), and is largely concerned with investigating the frequent logical errors we make in reasoning tasks. The normative standards governing the connections between one's beliefs and actions are principles of 'procedural rationality' (Bermúdez, 200I). They deal in relations of implication and entailment, providing a formal structure for setting out what ought to follow from a given set of premises. The kinds of outcomes that ought to follow are determined by logical functions operating between the premises and conclusion, which are syntactic, formal and content-free.

The notion that the connection between decision inputs and outcomes can be judged according to purely procedural norms therefore finds significant empirical and conceptual precedent (Stein, I996). Procedural rationality seems to be aligned with the aim of capacity legislation to focus on evaluating the process of decision-making rather than whether or not the outcome is objectively good or wise. If we take the premises or inputs as being analogous to the beliefs and values a patient holds, and the conclusion as analogous to the decision outcome, it looks as though the contents of these inputs and outcomes are irrelevant to the assessment: it is only the integrity of the inference that matters.

\section{The problem with process}

The challenge mooted earlier for a procedural conception of capacity was how to distinguish between a process of decision-making in which information had been used or weighed, from one in which it had not because of a mental impairment. The procedural view of rationality looks as though it ought to be able to help characterise the connections within the 'black box' of the decision-making process: the connections between the factors entering into the decision process and the outcome can be understood in terms of the logical relations between the beliefs, values and desires a person holds and the decision that he makes. A person is thus engaged in a successful decision-making process to the extent that these relations obtain in a specific instance of decision-making and the inferential structure from premises (beliefs, values, and so forth) to conclusion (decision outcome) is valid.

I have talked loosely of a person's beliefs, desires, values, and so forth, considering them as determinable starting premises upon which a process of decision-making operates to produce a recognisable outcome. If the norms of procedural rationality are to have traction on our behaviour, we need a determinate specification of what is referred to by 'the set of a person's 
beliefs, desires, values and so forth' in a particular instance (Heal, 2008). However, I query whether it is possible to circumscribe these as a set for the purposes of seeking to establish what kinds of decision outcomes ought to follow in the light of them. In the context of ordinary decision-making, belief desire - action relations do not form closed systems devoid of connections to a whole network of other relevant psychological elements. Rather, they are holistically interconnected with one another and with the world. Even if we could specify a set of starting premises from which to analyse the decision process, there is no way of determining in advance what other factors will be relevant to the processes of forming and revising one's beliefs and intentions: the concerns we bring to a decision-making process do not form a complete and closed system (Wiggins, I975). It is therefore not possible to ascertain whether the connections between inputs and outcomes in a particular instance of decision-making are procedurally intact, as the initial premises cannot be reliably established. Furthermore, we cannot establish in advance what a procedurally intact decisionmaking process would look like or what would constitute a breach of procedural criteria. Any generalisations we could make about the way information ought to be used in particular circumstances will hold only for the most part, and will always be defeasible. ${ }^{7}$

This suggests that the very idea of attempting to codify what the procedural relations between decision inputs and outcomes ought to be is misguided, as no rules can be precisely applied to ascertain what a procedurally rational process would look like. Tracing back through the account outlined thus far, the error arises when we attempt to break down the criterion of using or weighing information through analysing what procedural constraints might operate between the inputs into decision-making and its outcome in a particular instance. Reducing the process to the logical relations between isolated sets of beliefs, values and actions, although a prominent and robust strategy in cognitive psychology, fails to help us understand how the decision-making process functions in complex real-world situations, in which there are limitations on our cognitive capacities and many extraneous factors influencing our decision-making: 'our thinking and desiring life does not go on in a form which allows the demands of deductive logic, decision theory and so on to get a direct and unproblematic grip on it' (Heal, 2008, p. 56). In the clinical context, even circumscribing what information is relevant and needs to be understood for a simple procedure is difficult to pin down, and generates disagreement among clinicians (Gunn, Wong, Clare and Holland, I999), indicating that the information that needs to be taken into account when assessing capacity cannot be specified for the purposes of judging the relation between decision inputs and outcomes.

Moreover, the dictates of procedural rationality cannot provide normative guidance about how beliefs should be modified in the light of evidence or argument (Bermúdez, 200I). This is especially pertinent in the context of acquiring new information that is relevant to oneself and one's decisions, as is usually the case in assessments of capacity. Making decisions does not take the form of an argument or proof, but rather concerns the process by which we justify, change and revise our beliefs, desires and values (Harman, 2004). Procedural rationality can say nothing about how we ought to form beliefs and make decisions in the light of the information we have or acquire, or what factors are relevant to take into account when making a decision. On their own, procedural criteria cannot gain a purchase on what it means to engage in a normatively appropriate decision-making process: 'Logical powers, in the absence of suitably grounded beliefs ... are like an engine without fuel' (Audi, 2004, p. 4I). This insight is perhaps best demonstrated by the fact that individuals with schizophrenia frequently perform better than healthy controls on tasks of formal reasoning and

7 John McDowell makes an analogous argument in the case of ethics, denying the requirements of virtue can be precise: '[T]he best generalizations for how one should behave hold only for the most part. If one attempted to reduce one's conception of what virtue required to a set of rules, then ... cases would inevitably turn up in which a mechanical application of the rules would strike one as wrong' (McDowell, I979, p. 336). 
logic (Owen, Cutting and David, 2007). They are exceptionally good at being procedurally rational, but this does not entail that they are capable of accommodating important information into their decisionmaking, or making decisions that indicate they possess capacity.

To illustrate the impoverished perspective of the procedural view, consider a prime candidate for a procedural norm of reasoning that has been taken to be relevant to capacity assessment: consistency (Kennedy, I997). Consistency in one's beliefs, values and decisions and over time is, on the procedural view of rationality, a central normative ideal. Decision-theoretic approaches take it that maintaining internal consistency within one's mental economy is essential (Mele and Rawling, 2004, p. 4), and the norm of consistency epitomises the standards of procedural rationality, as it generally demands we do not hold openly contradictory beliefs and values (Bermúdez, 200I). Thus if procedural rationality is supposed to underpin capacity assessment, it is reasonable to presume that consistency should be a key criterion. Considering a specific instance of decision-making in isolation, obvious inconsistencies in what a person believes or values and what he ostensibly decides to do may indeed look bizarre and potentially hint at a lack of capacity. Kennedy (I997) suggests that a decision can be identified as having been made due to a pathology of belief or reasoning insofar as it is inconsistent with the patient's own previously expressed beliefs and values, irrespective of what the contents of those beliefs and values actually are. Evaluating the integrity of the decision-making process in this way might be a successful strategy in cases where capacity is temporarily impaired or fluctuating: expressing a choice that is out of kilter with one's own previously expressed beliefs and values may suffice to indicate a failure of logical relations between the inputs to the decision process and its outcome. Here, consistency is held up as a procedural norm by which to judge capacity.

However, internal consistency is defeasible as a procedural principle by which to assess decisionmaking. Holding inconsistent beliefs does not necessarily undermine the rational connections between one's beliefs, values and decisions, in part because the vast range and number we hold at any one time means that incongruities, inconsistencies or tensions are not always manifest. We hold numerous competing and incompatible beliefs, values and desires, and it is indeed part of the process of making a decision that we become aware of and modify these, change our minds and often make decisions that represent a compromise between such conflicts. Decision-making also needs to be tempered by practical considerations such as the time and cognitive resources one has available for resolving internal tensions or inconsistencies (Harman, 2004, p. 50). Furthermore, we may legitimately change our minds and adopt radically different views from those previously held. This is especially true in the context of medical decision-making, where often life-changing decisions are made, in the context of circumstances that have not been foreseen or previously considered. Although consistency may well be a component of good decision-making, we cannot ascertain what outcomes ought to follow from a consistent process, as there are innumerable different ways a consistent process could operate to produce different, but equally legitimate, outcomes. Hence the norm of consistency cannot form a criterion of decision-making.

There are two implications to draw out here. First, that beliefs, desires, values and whatever other factors enter into a decision-making process cannot be clearly circumscribed as a set of premises that bear logical relations only to one another and to the decision outcome. Beliefs and values can be indeterminate, held with differing degrees of conviction, and influenced by myriad other factors external to the immediate concerns of the decision process at hand, all of which affect what enters into the decision-making process and how these factors are used and weighed. There could potentially be any number of relevant beliefs that could legitimately shape a decision, but are unknown to the observer making a judgment about a person's decision-making. ${ }^{8}$ Second, attempting to view the procedural constraints on decision-making atomistically, by breaking

8 This is also to say nothing of the central role of emotion in decision-making, which has largely been underplayed in cognitive accounts of capacity (e.g. Charland, I998). 
down the process into its constituent components, leaves us with a frustrating lack of clarity about how connections between inputs and outcomes are supposed to function. The procedural approach to decision-making is misleading and impoverished when extrapolated from abstract theorising and applied to real-world contexts. This inherent complexity means that a distinction between an intact decision-making process indicative of capacity, and one in which capacity is impaired, cannot be drawn on a procedural basis. Yet, if purely procedural accounts of capacity do not work, how can the process of decision-making be judged, without recourse to making paternalistic judgments based on the contents of a person's belief and value system, and the decisions they make?

\section{Substantive features of decision-making}

The presence of a mental impairment may cause a person to hold beliefs that are unequivocally untrue, to the clear detriment of capacity. For example, in a case preceding the development of the MCA, a female patient refused an emergency caesarean section because she denied being pregnant. 9 Similarly, a patient suffering from anorexia nervosa who refused naso-gastric feeding because she believed she was still fat, was deemed to be incapable of acknowledging facts about her weight. ${ }^{\text {Io }}$ In these cases, the patients denied empirical truths that were irrefutable to the outside observer, and were judged to lack capacity on the grounds that their mental disorders impaired their ability to comprehend obvious facts about the world. In clinical practice, incapacity is also frequently found in patients experiencing delusions (Owen, David, Richardson, Szmukler, Hayward and Hotopf, 2009a). Legal precedents have established that clear epistemic breaches can undermine a decision-making process: 'a compulsive disorder or phobia may prevent the patient's decision from being a true one, particularly if conditioned by some obsessional belief or feeling which so distorts the judgment as to render the decision invalid.' ${ }^{\text {II }}$ Here, the patient refused a medically necessary hysterectomy on the grounds that she was childless and wanted children. However, she had two grown-up children, and the falsity of her belief thus undermined her capacity.

There is a clear substantive condition at work here in judgments about the particular epistemic commitments of patients: the beliefs held in these examples significantly impaired the patients' ability to make an autonomous decision. There is thus legal precedent for acknowledging that the content of beliefs in decision-making can indeed legitimately influence judgments of capacity. Given that capacity concerns what a patient is capable of understanding, and what he is capable of doing with the information given to him, there is a clear argument for taking into account what it is that the patient believes when assessing his capacity to decide. ${ }^{\text {I2 }}$

The question for the law is thus not whether substantive elements of decision-making ought or ought not to be taken into account in capacity assessments, but rather how and to what extent they can legitimately be accommodated. Allowing judgments about the content of a person's beliefs and values that inform a decision to enter into the capacity assessment runs the risk of violating the MCA's value-neutral intentions, undermining its moral objectives to respect autonomy as far as possible. Belief systems vary widely across cultures and communities, and there is a risk that

9 Norfolk \& Norwich Healthcare (NHS) Trust v. W[I996] 2 F.L.R. 6I3.

Io South West Hertfordshire Health Authority v. KB [1994b] 2 F.C.R. I05 I.

I I Trust $A$ and Trust B v. H (An Adult Patient) [2006] 2 FLR 958, at 965.

I2 Some authors have also suggested that the content of a person's values can in themselves be capacityundermining. For example, the extremely high value anorexia sufferers place on thinness may indicate a mental impairment influencing the decision-making process (Tan et al., 2006). However, making judgments about capacity based on a person's values does not have a recognised basis in case-law and is inevitably more controversial (e.g. Holroyd, 20I2). 
culturally sanctioned beliefs may be perceived as bizarre and potentially capacity-undermining by clinicians unfamiliar with the patient's cultural context. Furthermore, if the substantive elements of a person's decision-making influence the capacity assessment, the clinician's view about what it is or is not reasonable to believe, want or decide would become an inextricable part of the assessment (Kennedy, I997, p. 322).

The MCA is clear that the process of decision-making can, in principle, be influenced by unusual or eccentric beliefs and values, without detriment to the presumption of capacity. ${ }^{13}$ This leaves us with a dilemma: procedural accounts cannot distinguish capacity from incapacity, but judging the substantive features of decision-making may lead to clinicians making illegitimate judgments about patients' capacity, on account of their unusual beliefs or decisions that are thought to be unwise. I suggest that it is possible to navigate between these two difficulties by taking a compromise position that combines the strength and objectivity of a procedural view with the necessary practicality of acknowledging the role of substantive features in judging a person's capacity. Rather than considering assessment in terms of acceptable procedural aspects of decision-making, as distinct from substantive (and thus unacceptable) aspects, more focus should be given to identifying how the procedural and substantive features of decision-making interact. It is this interplay that can supply the best guide as to whether the patient is successfully engaged in a decision-making process indicative of capacity.

\section{Process and content}

Decision-making requires us to draw on available sources of information and vast amounts of background data. One must have the capacity to accept particular premises, reject others, consider the testimony of others, appeal to one's knowledge of the way the world is, and call prior beliefs into question in the light of counter-evidence. Decision-making is essentially steeped in the context of one's own particular circumstances, enabling successful action in the world in the way that one intends. Hence whether the process is indicative of capacity or not is at least partially dependent on whether the decision outcome actually serves this role in connecting with and acting on the world.

I have argued that attempting to judge the process of decision-making in terms of its adherence to procedural criteria leads us down the wrong path and breeds misconceptions about what an unimpaired process of decision-making looks like. The same is true of attempting to judge the content of a decision: in itself it can be neither good nor bad, wise nor unwise, appropriate nor inappropriate. What makes the decision indicative of capacity is that it reasonably follows in the light of the information given, the person's beliefs, values, and so forth, and will likely have the desired effect given the particular context in which the decision is being made. This assessment is inherently both content-laden and procedural: the decision content and the process by which it is formed are not conceptually separable elements of decision-making.

To elaborate on why it is the combination of procedural and substantive features, rather than either on their own, that should determine capacity assessments, let us consider the example of delusions. Often delusions take the form of a highly elaborate set of beliefs and desires, each mutually consistent with one another and entirely inferentially valid, and patients may deliver procedurally intact reasoning in defence of their claims (Bermúdez, 200I, p. 47I; Kemp, Chua, McKenna and David, I997). On a procedural account, no deficit or impairment in decisionmaking may be identifiable. By the same token, if we examine the contents of delusional beliefs,

I3 For example, $\operatorname{Re} C$, concerning an individual with schizophrenia who was deemed to possess the capacity to refuse a medically recommended amputation of his gangrenous foot, despite his delusional belief that he was a famous doctor and would not die from his condition. 
there is no clear-cut way of distinguishing them from beliefs that are bizarre or eccentric but ultimately

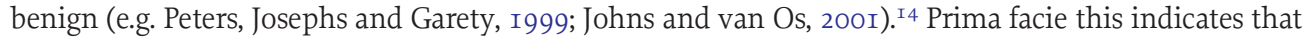
evaluating substantive features alone cannot distinguish capacity from incapacity. The most promising line of demarcation between a delusional belief and a non-delusional belief is rather that the person entertaining a delusion is unable or unwilling to reason about, justify and be open to the possibility of revising that belief in the face of counter-evidence or argument (Spitzer, I990, p. 39I). What strikes us as unusual in such cases is a failure to afford due weight and significance to the available evidence that runs counter to the delusional conviction. This is not a matter of agreeing or disagreeing with the truth of the particular beliefs an individual holds, but rather perceiving a deficit in the processes by which significant facts about the world are grasped, accommodated and used in the formation, maintenance and revision of beliefs, and in the forming of intentions to act. It is attributable to neither a procedural deficit nor a substantive one, but an apparent breakdown in the relations between the individual's normal, general beliefs about the world and those that are guiding that particular instance of decision-making. Somewhere in the process, both procedural and substantive features of decision-making have gone awry.

\section{Recognisable reasons}

How can the interplay between procedural and substantive elements of decision-making best be conceptualised? I suggest it is fruitful to consider one idea presented in the conceptual literature on capacity, but that has not been further developed. In an early article on the notion of decisional competence to consent to treatment, Freedman (I98I) argues that what it means for a person to have capacity with regard to a decision is that he is capable of providing 'recognisable reasons' for his decision. On this view, if a mental impairment is suspected, a person must have reasons that are relevant to the decision he makes in order to be deemed to possess capacity.

Ordinarily, our decisions and actions are not guided by well-thought-out reasons, and it would be an overly stringent demand that a patient needs to articulate reasons for his decision in order to be judged to have capacity. However, evaluating a person's decision-making process for the purposes of determining whether or not he has a capacity-undermining impairment requires a more critical and rigorous consideration of his decisions than ordinary decision-making, particularly where the decision to be made has potentially serious consequences for the patient's health and wellbeing. On the view I am advocating, an attempt to grasp a patient's reasons for a decision can in fact be of practical use for clinicians, and for the courts involved in making fine-grained judgments about a person's capacity, providing the notion of 'reasons' can be adequately conceptualised. It has been suggested that the notion of rationality may be a key constitutive factor in understanding mental capacity (Owen et al., 2009b), and, as such, patients' reasons for their decisions deserve conceptual scrutiny. Examining reasons may provide a way of considering decision-making in terms of both procedural and substantive elements, one that encompasses all the aspects of the capacity test set out in the MCA. This is because having a reason for a decision requires both procedural integrity, following in the light of one's beliefs, and substantive appropriateness, in that it has some grounding in reality or socially sanctioned beliefs. Reasons guide decisions and make them intelligible to an outside observer, functioning by enabling us 'to see the events or attitudes as reasonable from the point of view of the agent' (Davidson, I982/2004, p. I69). Conversely, in the absence of recognisable reasons we might think of an action or decision as failing to result from a legitimate process. ${ }^{15}$

I4 Differentiating between legitimate religious beliefs and pathological ones is recognised as a particularly problematic area of judgment (Waldfogel and Meadows, I996).

I 5 This view is consistent with the 'accessible ends' approach to rationality developed by O'Neill (200o), whereby a person's decision-making is judged according to whether their ends, norms and evaluative and epistemic 
Consider a few examples to illustrate the utility of an appeal to reasons in understanding a decision-making process:

I A man refuses potentially life-saving surgery to remove a cancerous tumour from his liver. When asked why he refuses, he glances out of the window and says with sincerity 'because the number 23 bus just went past'.

2 An artistic patient is being treated for bipolar disorder, but decides, against medical opinion, to refuse to take lithium. She tells her doctor that she believes this treatment diminishes her creativity and ability to appreciate colours, and she does not like the side effects it causes. ${ }^{\mathrm{I}}{ }^{6}$

3 A patient has suffered a head injury and as a result of surgery now has a large lump on his head and several stitches. He believes the FBI have implanted a radio transmitter in his skull and has made several attempts to sue them for invasion of privacy. He refuses any further medical intervention to reduce the swelling and minimise the risk of permanent brain injury, as he believes this is a further attempt at mind control. ${ }^{\mathrm{I}}$

In all three of the above cases, patients give reasons for the decision being reached, but they do not all possess the same status as recognisable reasons. In the first case, there is no logical or semantic connection between the location of the number 23 bus and a response to the option of surgery: the two states of affairs simply have no bearing on one another whatsoever. The man's stated reason therefore cannot be a reason for his decision. If this were the sum total of the patient's reasoning, clinicians would be justified in querying his capacity to refuse treatment. It may be possible that the number 23 carries some special and particular significance for the man that uniquely tells him something about the risks of his having surgery, so that in some roundabout way the salience of the bus route is connected to his decision, but the point here is that for the outside observer, there is no relation between the two and therefore his reason is not recognisable as such. There is no connection between the action and the reason the agent gives for it, as far as the clinician can ascertain. I suggest that the lack of a recognisable reason here captures an important sense in which the patient is failing to understand, use or weigh information in coming to a decision: appealing to recognisable reasons is a useful shorthand for picking out a problem in the decision process that does not require a conceptual separation between procedural and substantive aspects of decision-making.

In the second case, we have a common scenario in which a patient wishes to go against medical opinion and refuse a recommended treatment. This patient places a very high value on her ability to create artistic works, and so for her any medication affecting this ability will be extremely undesirable. Weighed in the balance against the advantages of taking such medication, such as a levelling out of mood, the patient places a higher value on her creative capacity. She has recognisable reasons for her decision coherently based on her belief and value system, and there is a clear logical connection between her given reasons and her decision. It is unlikely in this situation that the patient's capacity would be undermined. Again, the appeal to reasons has practical benefits: it means that one need not share the patient's own values to perceive how her decision follows from what she believes and understands, and no evaluative judgment needs to be made about the content of her belief and value system in order to assess her capacity.

commitments can be appreciated and seen as intelligible by others, irrespective of whether those commitments are themselves shared.

I6 Cited in Fulford (2004).

I7 Cited in Gold and Howhy (2000). 
It is the third case that is likely to cause the most trouble for clinicians attempting to ascertain the patient's capacity, and it highlights the conceptual concerns central to capacity assessments. Clearly the patient holds delusional beliefs, but these provide him with reasons for his action. We can understand how, given the belief that the FBI was interfering with his brain, and his taking his wound and stitches as evidence in support of this belief, the patient was seeking redress for the harm caused to him, and justifiably refusing any further medical intervention on those grounds. These reasons may not be good reasons, in that their epistemic basis is far from secure: the man ignores the more straightforward and compelling explanation that the lump and scar on his head resulted from surgery to treat a head wound, and that his life is potentially in danger if he does not consent to further treatment. Nonetheless, there is a recognisable relation between having such a belief and acting in the way that he does.

Does an appeal to recognisable reasons prove useful in this context? I suggest that it does, particularly given the use made of the notion of 'irrational reasons' in the influential Re $M B$ and Re $T$ rulings. In both rulings, the presumption of capacity was strongly enforced, and having 'irrational reasons' was explicitly deemed not to undermine capacity. However, exploring borderline cases such as the third example above points to the need to further and better specify what irrational reasons are, and under what circumstances they may or may not indicate impaired capacity. Clearly, irrational reasons can sometimes offer evidence of incapacity (if not a definitive judgment). In case (I), the reason given for treatment refusal is not so much irrational as entirely arational: having not even a semblance of a reason for the decision being made. The patient in case (3) is more complex. He could be considered to have an irrational reason for his decision: a term that captures the intuitive sense in which the reasoning process has gone awry. Although his decision is rational to the extent that it follows procedurally from his beliefs, his reasons are not responsive to significant facts about the world and he appears unable to countenance any other explanation for his wound. From this point, assessment of his capacity could be argued both ways. His capacity to refuse the treatment on offer is unclear, and it is beyond the scope of this article to consider more fully whether his reasons are in fact legitimate. ${ }^{18}$ What is clear, however, is that the judiciary's reference to 'irrational reasons' needs to be further specified if it is to provide a useful benchmark; we need to cash out the ways in which reasons might be irrational but nonetheless recognisable as supporting a decision outcome, and also the ways in which an irrational reason might provide evidence for a capacity-undermining impairment. To this end, a fuller account of the significance of patients' reasons in judging capacity is warranted.

This brief exploration suggests that there is complex structure to the reasons that explain or account for one's actions and decisions, and that in some cases it is clear where this structure fails. This failure is not characterisable in terms of a violation of specific procedural or substantive norms, but the absence of a recognisable reason for the decision outcome points to a normative failure of some kind in the process. Despite the rhetoric of the Re $M B$ ruling, if a mental impairment is suspected, then the reasons a patient has for refusing treatment may indeed be subject to scrutiny in an assessment of capacity (Stauch et al., 2006). It is open to debate quite how to characterise what counts as a recognisable reason, but considering capacity in this way does confer distinct advantages on the assessment process. Couching an understanding of the decisionmaking process in terms of reasons prevents us from slipping into the illusion that the difference between success and failure on the capacity test turns on an elusive procedural connection between inputs and outputs.

This strategy also enables us to acknowledge that the contents of a patient's beliefs, values and desires may indeed influence how their decision-making is perceived, whilst alerting us to the fact

I8 A further analysis of what could legitimately count as a reason would require taking into account 'what norms have force within the relevant social practice and contexts' (Anderson, 2003, p. I03). 
that eccentric or unusual beliefs and values may be perfectly legitimate if they play the right kind of normative role in the decision-making process. This proposal therefore does conflict with the proclaimed value-neutrality of the MCA, because what patients believe, value and want to do does, in practice, affect judgments about whether or not they are capable of making a decision. This is not a negative consequence. The procedural capacity criteria cannot distinguish whether an apparently irrational decision is the product of a mental impairment or not, and so they cannot be sufficient for clinical judgments about a person's decision-making capacity. But the proposed alternative does not slide into unwarranted paternalism, because it does not involve making evaluative judgments solely about the contents of a patient's beliefs or desires, judging them to be rational or irrational, or in themselves 'pathological'. Rather, what matters in an assessment of capacity is how these beliefs and values interact with information about the proposed treatment, how coherently they fit with the person's broader belief and value system, and whether the decision outcome reasonably follows in the light of everything the patient knows about the decision being made. I suggest that understanding incapacity as a failure to have recognisable reasons for one's decision therefore provides a way to conceptualise capacity that avoids the pitfalls of either a procedural or substantive approach. It allows a more nuanced and sophisticated way of assessing capacity than the procedural test alone allows, whilst preventing undue medical paternalism being exercised, as clinicians cannot simply dismiss decisions that are perceived to be unwise if they are recognisably reasonable from the point of view of the patient.

This proposal may go some way towards reducing the tension between the law as it stands and the judgments of clinicians in difficult psychiatric cases. In clinical practice, construing successful decision-making in terms of having recognisable reasons for one's decision allows more scope to acknowledge the complexities and subtleties involved in the process, without reducing assessment to a test of cognitive functioning. Unlike the MCA criterion of 'using or weighing information', appealing to reasons explicitly acknowledges that both procedural and substantive elements of the decision-making process are being evaluated in a capacity assessment.

\section{The role of context}

Appealing to the recognisable reasons a person has for his decision generates an important consequence for understanding how the decision-making process can be assessed, as it creates conceptual space for the context of decision-making to come to the fore. Rather than seeking to narrow the scope of a judgment through characterising specific criteria by which to judge particular instances of decision-making, it is fruitful instead to broaden the perspective from which an assessor seeks to understand the decision process, encompassing something of the context in which the decision is being made, and the circumstances of the decision-maker. This is not merely a practical consideration, as awareness of the context provides a broad background against which potential impairments to capacity, where decision-making is going wrong, can be picked out.

Take a hypothetical example of a person suffering from anorexia who refuses to eat. Premised on his high valuation of thinness he may look as though he possesses decision-making capacity, since we cannot identify any impairment or failure of relations between the beliefs and values influencing his decision and the decision outcome itself. But in isolating this particular decision process, the values and beliefs he holds have been taken out of the broader context in which they occur and the potentially capacity-undermining nature of the decision process cannot be identified in this way. If, on the other hand, we take capacity assessment to pertain to a particular decision whilst fully acknowledging the contextual embeddedness of the factors entering into that decision within the person's own life, and explore the reasons for his decision, then we are in a far better position to assess whether the decision outcome is the result of a process indicative of capacity. These 
contextual factors may include explorations of the patient's own perceptions and evaluations of his condition, attitudes towards his health, aspirations or expectations of the future, belief in the efficacy of treatment, trust in the medical professionals treating him, relationships with caregivers, and so on, together with the severity of the consequences of not making a decision, or of the decision being a potentially life-threatening one. The kinds of factors relevant to his reasons and the assessment cannot be specified in advance or reduced to a set of criteria, but developing some broad brushstrokes of the background to the decision being made may enable a more sophisticated understanding of the decision outcome to be made by the assessing clinician. Contrary to the checklist tendency to break down the decision process into its constituent parts, taking a holistic and context-laden approach to capacity is likely to render a person's decision more intelligible, highlighting where there is an obvious breakdown in the relations between all the factors involved in the decision-making process.

\section{Conclusion}

Any adequate conception of capacity must distinguish a process of decision-making indicative of capacity from one that is impaired. Attempting to pin down this distinction by adopting a procedural account of capacity relies on the idea that the logical relations between inputs and outcomes, construed as analogous to an inference, can serve this purpose. However, I have argued that this approach is inadequate in real-world decision-making contexts, as innumerable factors may enter into the process, and it is not possible to specify on procedural grounds how information ought to be accommodated and used in making a decision. The distinction between the success and failure of a decision process cannot be drawn by assessing the procedural elements of decision-making alone. Judgments of capacity require the acknowledgement of the complex, context-rich processes of decision-making. Both procedural and substantive elements are involved in determining whether a person is able to make a decision that, loosely, is appropriate, given the range of factors that enter into the decision-making process.

Viewing the decision-making process in terms of having a recognisable reason for one's decision offers a way to accommodate this broader view, which reconciles both procedural and substantive elements of decision-making. This approach allows the decision to be understood within its context for the individual, whilst not prejudging the content of the decision or the factors that influence it as either acceptable or indicative of pathology. This enables the assessment to avoid the charge of risking unwarranted medical paternalism, regarding what a patient ought to believe or want. In assessing capacity, clinicians and the courts ought to acknowledge that procedural and substantive elements interact in patients' decision-making, and that exploring reasons for their decisions might shed more light on the decision-making process than assessments of procedural criteria alone would permit.

Although case-law acknowledges this complex interplay and the difficulties of determining capacity in borderline cases, in ordinary practice the criterial MCA test is liable to narrow clinicians' judgments and prevent further reflection on how assessments of capacity are guided by both procedural and substantive norms. The conceptual shift proposed here would require interpreting the legal test of capacity in a way that would inherently allow more scope for clinical expertise and judgment than a reductive box-ticking approach to the criteria. I do not consider that this is necessarily to the detriment of capacity assessments: they are complex, subtly balanced and contingent on a range of normative judgments, and it is better to acknowledge this complexity than to dismiss it in an attempt to simplify the judgment required. Whilst this approach cannot maintain the value-neutrality intended by the MCA, assessing decision-making through exploring patients' reasons could enable more sophisticated clinical judgments of capacity to be made. Such critical reflection on the legal criteria for capacity and how they are 
interpreted in clinical practice is essential to ensuring the right to autonomy in decision-making is protected as far as possible.

\section{References}

anderson, J. (2003) 'Autonomy and the Authority of Personal Commitments: From Internal

Coherence to Social Normativity', Philosophical Explorations 7(2), 90-I08.

ashton, G., LetTS, P., oAtes, L. and terRell, M. (2006) Mental Capacity: The New Law. Bristol: Jordan Publishing.

AUdI, R. (2004) 'Theoretical Rationality: Its Sources, Structure and Scope', in A. R. Mele and P. Rawling

(eds), The Oxford Handbook of Rationality. Oxford: Oxford University Press, I7-44.

BERMúdez, J. L. (200I) 'Normativity and Rationality in Delusional Psychiatric Disorders', Mind \&

Language I6(5), 457-93.

Charland, L. C. (I998) 'Is Mr Spock Mentally Competent? Competence to Consent and Emotion',

Philosophy, Psychiatry \& Psychology 5(I), 67-8I.

culver, C. M. and Gert, B. (2004) 'Competence', in J. Radden (ed.), The Philosophy of Psychiatry: A

Companion. New York: Oxford University Press, 258-7I.

Davidson, D. (I978/200I) 'Intending', in D. Davidson, Essays on Actions and Events. Oxford: Oxford

University Press, 83-102.

DAvidson, D. (I982/2004) 'Paradoxes of Irrationality', in D. Davidson, Problems of Rationality. Oxford:

Oxford University Press, I69-88.

Department of Constitutional affairs (2007) Mental Capacity Act 2005: Code of Practice. London: The

Stationery Office.

EYSEnCK, M. W. and KeAnE, M. T. (2005) 'Reasoning and Deduction', in M. W. Eysenck and M. T. Keane,

Cognitive Psychology: A Student's Handbook, 5th ed. London: Psychology Press, 506-532.

FREEDMAN, B. (I98I) 'Competence, Marginal and Otherwise: Concepts and Ethics', International Journal of Law and Psychiatry 4(I/2): 53-72.

Fulford, K. W. M. (2004) 'Ten Principles of Values-Based Medicine’, in J. Radden (ed.), The Philosophy of

Psychiatry: A Companion. New York: Oxford University Press, 205-234.

GolD, I. and HоwнY, J. (2000) 'Rationality and Schizophrenic Delusion', Mind \& Language I 5(I), I 46-67. grisso, T., Appelbaum, P. S. and hill-Fotouni, C. (I997) 'The MacCAT-T: A Clinical Tool to Assess

Patients' Capacities to Make Treatment Decisions', Psychiatric Services 48(II): I4I5-I9.

Gunn, M. J., wong, J .G., Clare, I. C. H. and holland, A. J. (I999) 'Decision-Making Capacity', Medical Law

Review 7: 269-306.

Harman, G. (2004) 'Practical Aspects of Theoretical Reasoning', in A. R. Mele and P. Rawling (eds), The

Oxford Handbook of Rationality. Oxford: Oxford University Press, 45-56.

HEAL, J. (2008) '“Back To The Rough Ground!” Wittgensteinian Reflections on Rationality and Reason',

in J. Preston (ed.), Wittgenstein and Reason. Oxford: Blackwell, 47-64.

HOLRoyd, J. (20I 2) ‘Clarifying Capacity: Values and Reasons', in L. Radoilska (ed.), Autonomy and Mental

Disorder. Oxford: Oxford University Press, I45-69.

HURLey, S. and NudDs, M. (2006) Rational Animals? Oxford: Oxford University Press.

Johns, L. C. and van OS, J. (200I) 'The Continuity of Psychotic Experiences in the General Population',

Clinical Psychology Review 2I: II 25-4I.

KACELniK, A. (2006) 'Meanings of Rationality', in S. Hurley and M. Nudds (eds), Rational Animals?

Oxford: Oxford University Press.

Kemp, R., ChUA, S., MCKenNa, P. and DAvid, A. S. (I997) 'Reasoning and Delusions', British Journal of

Psychiatry I70: 398-405.

KenNedy, I. (I997) 'Commentary on Re MB (Medical Treatment)', Medical Law Review 5: 317-53.

LAW Commission (I995) Report No. 23I. Mental Incapacity. London: HMSO. 
MCDOWELL, J. (I979) 'Virtue and Reason', The Monist 62: 33I-50.

mele, A. R. and Rawling, P. (eds) (2004) The Oxford Handbook of Rationality. Oxford: Oxford University Press.

o’NeILL, O. (2000) Bounds of Justice. Cambridge: Cambridge University Press.

owen, G. S., cutting, J. and David, A. S. (2007) 'Are People with Schizophrenia More Logical than

Healthy Volunteers?', British Journal of Psychiatry i91: 453-54.

owen, G. S., DAVID, A. S., richardson, G., SZMUULER, G., HAYWARD, P. and hotopf, M. (2009a) 'Mental Capacity,

Diagnosis and Insight in Psychiatric In-patients: A Cross-sectional Study', Psychological Medicine 39: I389-98.

owen, G. S., Freyenhagen, F., Richardson, G. and hotopf, M. (2009b) 'Mental Capacity and Decisional

Autonomy: An Interdisciplinary Challenge', Inquiry 52(I): 79-I07.

PETERS, E. R., JOSEPHS, S. A. and GARETy, P. A. (I999) 'Measurement of Delusional Ideation in the Normal

Population: Introducing the PDI (Peters et al. Delusions Inventory)', Schizophrenia Bulletin 25: 553-76. RAz, J. (I999) 'Explaining Normativity: On Rationality and the Justification of Reason', Ratio I 2: 354-79. SPItzer, M. (I990) 'On Defining Delusions', Comprehensive Psychiatry 3I(5): 377-97.

stauch, M., wheat, K. and tingle, J. (2006) Text, Cases and Materials on Medical Law. New York: Routledge Cavendish.

stein, E. (I996) Without Good Reason: The Rationality Debate in Philosophy \& Cognitive Science. Oxford: Clarendon Press.

TAN, J. O. A. and HOPE, T. (2008) 'Treatment Refusal in Anorexia: A Challenge to Current Concepts of Capacity', in G. Widdershoven, J. McMillan, T. Hope and L. van der Scheer (eds), Empirical Ethics in Psychiatry. Oxford: Oxford University Press, I87-2 I0.

tan, J. O. A., hope, T. and stewart, A. (2003) 'Competence to Refuse Treatment in Anorexia Nervosa', International Journal of Law \& Psychiatry 26(6): 697-707.

TAN, J. O. A., STEWART, A., FITZPATricK, R. and hope, T. (2006) 'Competence to Make Treatment Decisions in Anorexia Nervosa: Thinking Processes and Values', Philosophy, Psychiatry \& Psychology I3(4): $267-82$.

viglione, V., muratori, F., maestro, S., brunori, E. and picchi, L. (2006) 'Denial of Symptoms and Psychopathology in Adolescent Anorexia Nervosa', Psychopathology 39(5): 255-60.

WALDFogel, S. and MEAdows, S. (I996) 'Religious Issues in the Capacity Evaluation', General Hospital Psychiatry I8(3): 173-82.

Wiggins, D. (1975) 'Deliberation and Practical Reason', in D. Wiggins, Needs, Values, Truth: Essays in the Philosophy of Value. Oxford: Basil Blackwell, 215-37. 